\title{
Sub-microsecond Response Digital Controller for POL
}

\author{
Hirotaka Nonaka /Nagasaki University \\ Graduate School of Engineering \\ Nagasaki Univ. \\ Nagasaki,Japan \\ bb35210144@cc.nagasaki-u.ac.jp \\ Kenji Mii/Nagasaki University \\ Graduate School of Engineering \\ Nagasaki Univ. \\ Nagasaki,Japan
}

\author{
Daisuke Kanemoto/University of Yamanashi \\ Faculty of Engineering \\ The Univ. of Yamanashi \\ Yamanashi,Japan \\ dkanemoto@yamanashi.ac.jp
}

\author{
Yoichi Ishizuka /Nagasaki University \\ Graduate School of Engineering \\ Nagasaki Univ. \\ Nagasaki,Japan \\ isy2@nagasaki-u.ac.jp \\ Fumiaki Takenami \\ Graduate School of Engineering \\ Nagasaki Univ. \\ Nagasaki,Japan
}

\begin{abstract}
This paper will discuss about the proposed hard-ware logic type digital controller for on-board SMPS which has a very small time-delay in control loop. Some experimental has been done including estimation of the load current change experiment and the frequency characteristic of open loop transfer function. These result reveal the proposed circuit could be suppressed the time delay to submicrosecond order. To use the multi-phase system reduces the output ripple.
\end{abstract}

Keywords—DPWM,Point of Load(POL),Digital Control

,Multi-Fhase

\section{INTRODUCTION}

Digital electronic products have been spreading quickly by the advancement of the integrations technologies. ICs, DSPs and FPGAs require a high performance and a high speed due to the trend. Along with the situations, the power consumption is increasing. To suppress the power consumption, the power supply voltage is getting lower toward to sub $2 \mathrm{~V}$. Figure 1 shows the relation between size of LSI and margin of $V_{D D}$. The trend of future size of LSI and margin of $V_{D D}$ are going to become lower and more severe. Because of the severe voltage margin by the lower power supply voltages, special SMPS, point of load (POL) is disposed very near to the load. The requirements of the control circuit of POL are high accurate, high speed, adaptive and low cost. For the control purpose, pulse width modulation (PWM) control is a one of appropriate technique. Digital control or DPWM can accomplish robust and flexible power control with soft-tuned parameters and will become popular control technique. Although, there are some disadvantages in cost and speed, against analog control circuit. Proposed hardware-logic based digital PWM control circuit is effective to such requirements.
In this paper, trend and problems of DPWM controller for POLs is introduced at first. At the next, the proposed DPWM control method's principles of operation and circuit configurations are described. At last, the effectiveness of the proposed technique is confirmed with some experiments and comparison between prior works and prototype proposed circuit is introduced.

\section{DPWM CONTROL METHOD FOR POL}

\section{A. Current State of DPWM Controller for POL}

Before describing the proposed digital control system for POL, trend of digital controllers for POLs are summarized. The trend is categorized with some keywords, which are treated in these papers [2]-[21] that treat DPWM control, in Fig. 2.

We have found that most of the paper treats the transient response performance, small size and power consumption. In contrast, the cost has not been discussed so much. But this point cannot be ignored because the cost is also important in the real electronic products.

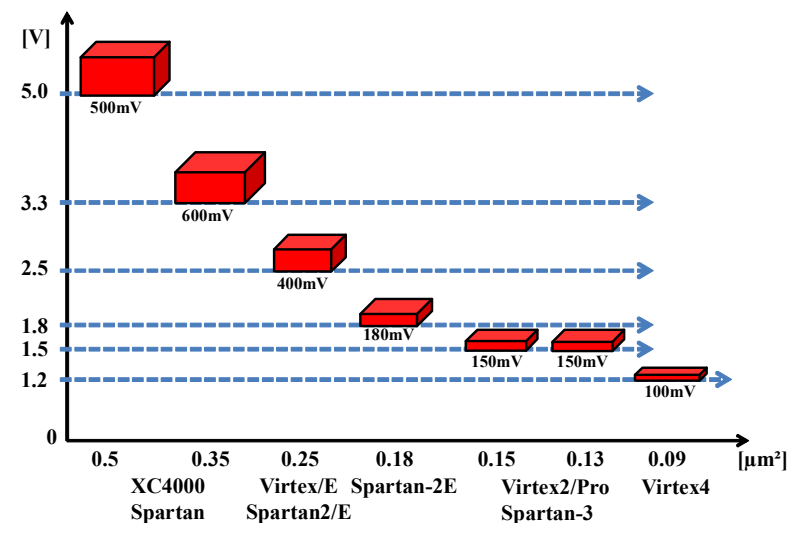

Fig. 1 The relation between size of LSI and margin of $V_{\mathrm{DD}}$ 


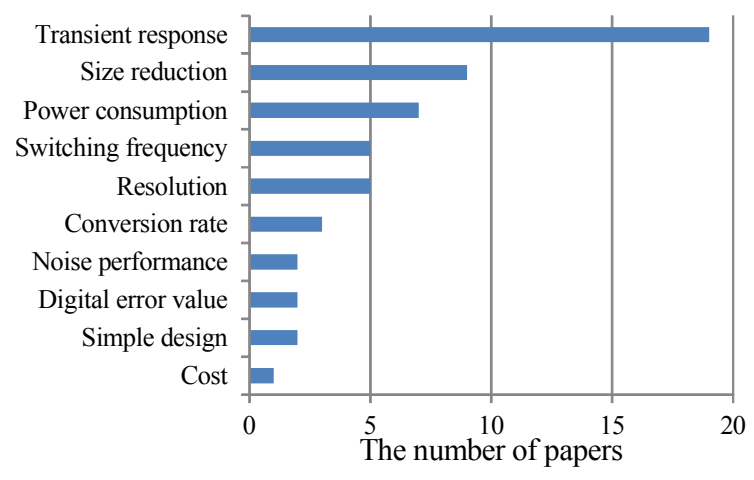

Fig. 2 Key point of DPWM controller and number of papers

Therefore, designing good DPWM controller, is taking balance of all of the factors including the cost. .

In the next section, the problems about the restrict factor of high-speed response of DPWM control are described.

\section{B. The Circuit Configuration of General DPWM Controller for POL}

The circuit configuration of general DPWM controlled POL is shown in Fig.3(a). This topology has two major time-delay problem. First, time-delay occurs at $\mathrm{A} / \mathrm{D}$ converter with the conversion-delay. And, the calculation time of digital controller is another problem. Both of the time-delay directly effects on the response speed of the control circuit and influences stability of the control. Total of the delay time will be described as the discrete delay factor $e^{-L s}$ in the control loop shown in Fig.3(b). In general, total of the delay time is $600 \mathrm{nsec}$ at least excepting the delay time of driver circuit.

\section{The Circuit Configratin of Proposed DPWM Controller for $P O L$}

Main POL circuit is a quite ordinary non-isolated buck converter. The control circuit is composed with $\mathrm{D} / \mathrm{A}$ converter, analog comparator, digital controller and drive circuit.

The analog timing converter (ATC) block shown in Fig.4(a) is composed with D/A converter and analog comparator. In Fig.4(b), the control block diagrams are shown. ATC block, PID control calculation block and upcounter block for gate pulse creation, are all in parallel and synchronized with the system clock $f_{C L K}$.

\section{The control circuit configuration of the proposed $D P W M-P O L$}

Figure 5 shows the precise control circuit configuration, and Fig. 6 shows control signal flow of the proposed DPWM-POL. Let's take a look at the signal flow.

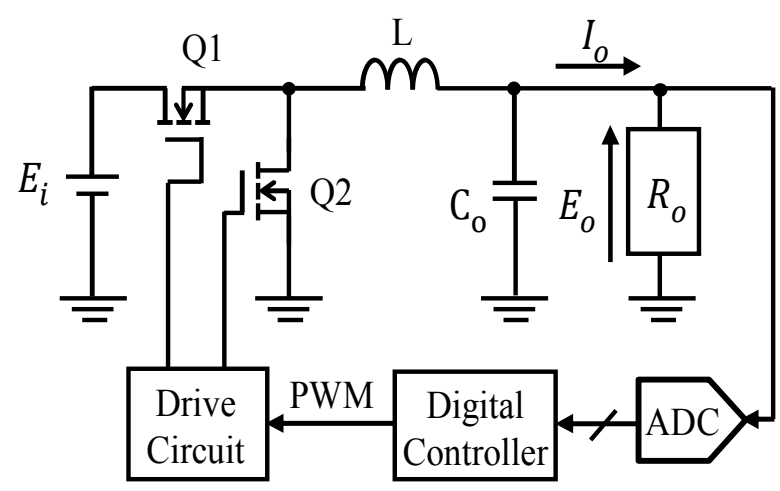

(a) Circuit configuration

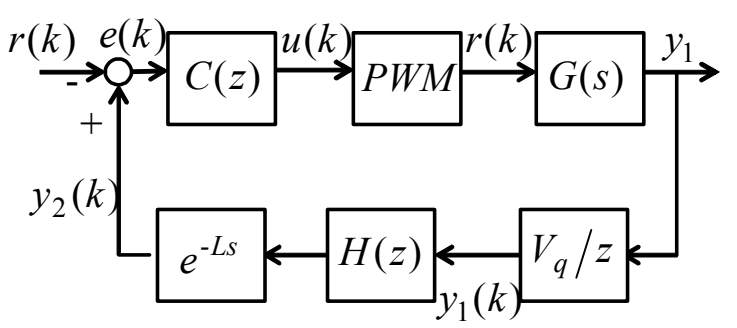

(b) Control block

Fig.3 General DPWM-POL

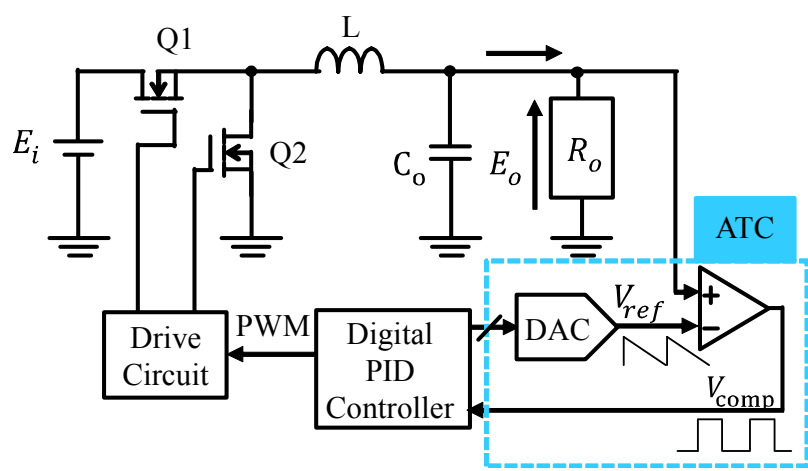

(a) Proposed DPWM-POL

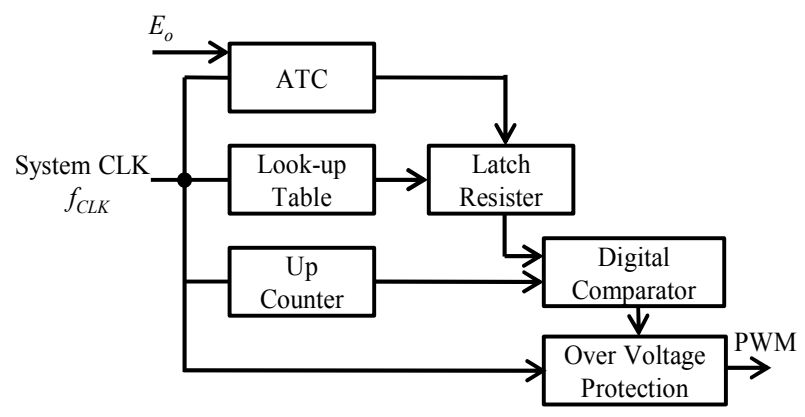

(b) Control block

Fig.4 Circuit configuration of proposed DPWM-POL 
As mentioned above, all blocks are synchronized with the system clock $f_{C L K}$. Memory 1 is used the look-up table method, and can store waveform values not only triangle or saw tooth but any waveforms. In this paper, the stepdown saw tooth wave form is employed. $V_{\text {ref }}{ }^{+}$is the maximum output voltage of DAC. The output voltage $E_{o}$ of POL is compared with the output voltage of $\mathrm{D} / \mathrm{A}$ converter in the ATC block, successively. The comparator's output is read out to the latch signal to each D-ff at the timing that $E_{o}$ was sensed. Also, the look-up table method is used for the duty ratio calculation with memory 2, 3 and 4. Especially, the duty ratio data which is pre-calculated with the value of $E_{o}$, are stored in memory 2 .

The duty ratio data is read out from memory2 according to $f_{C L K}$. At the timing of $E_{o}$ sensed, one of the duty ratio data is chosen and transferred to $u(k)$ in D-ff4, where $k$ is the number of switching term.

Because of the small delay of this control technique, the sensed $E_{o}$ data can reflect on-term of the same switching term.

At the digital comparator, $u(k)$ is compared with upcounter data, and converted to real-time analog PWM waveforms. On-term $T_{o n}(k)$ of DPWM signal of switching term $k$ is decided by $u(k)$. In parallel with the processing of ATC block, the $u(k)$ is called with system clock and latched by ATC output as trigger. At the last of the switching term, $u(k)$ is preset maximum value by PR signal generator for preparing next term.

The delay of the proposed control circuit is mostly dominated with the calling and the loading time of memory 2 .

\section{E. PID control with Look-up Table}

$u(k)$ which is stored in memories is pre-calculated by general PID digital control laws as

$$
u(k)=u_{r e f}+K_{P} e(k)+K_{I} n_{I}(k)+K_{D}(e(k)-e(k-1))
$$

where $u_{r e f}$ is a reference value of $u(k), e(k)$ is an digitalized error value between $r$ which is digitalized reference voltage $V_{r e f}$ and, $y_{1}(k)$ is output data of upcounter in switching term $k$ as

$$
e(k)=y_{1}(k)-r
$$

$K_{P}, K_{I}$ and $K_{D}$ are a proportional gain, an integral gain and an derivative gain, respectively, $n_{I}(k)$ is integral factor, that is

$$
n_{I}(k)=n_{I}(k-1)+e(k)
$$

At the timing of the latch signal is becoming high, $y_{1}(k-1)$ is latched to $y_{2}(k-1)$ as

$$
y_{2}(k-1)=y_{1}(k-1)
$$

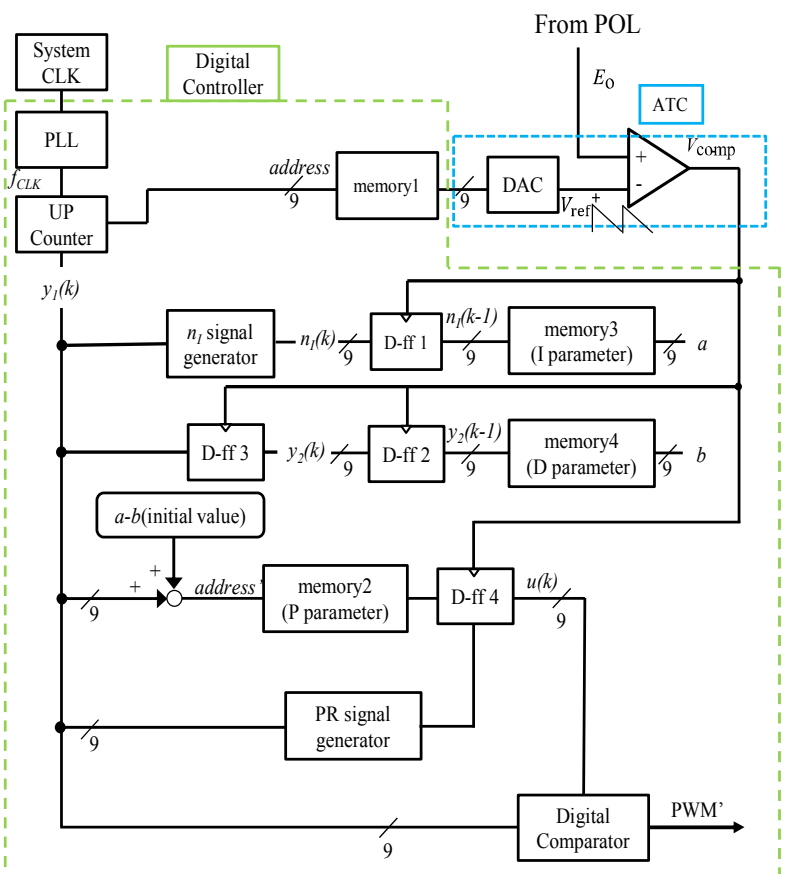

Fig. $\overline{5}$ The system configuration of proposed control circuit

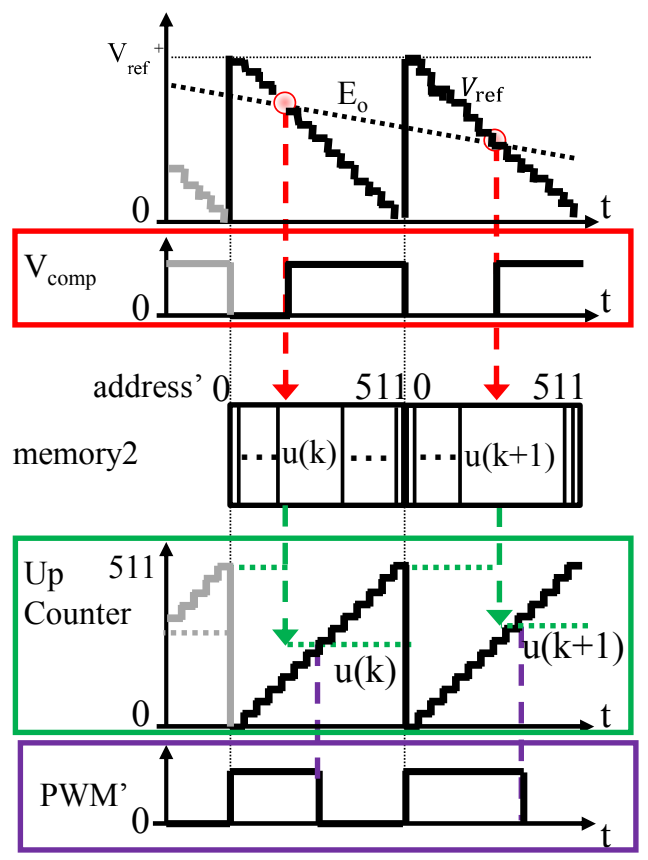

Fig.6 Control signal flow

TABLE I Address and data of memory2 at $K_{P}=5, K_{I}=0$

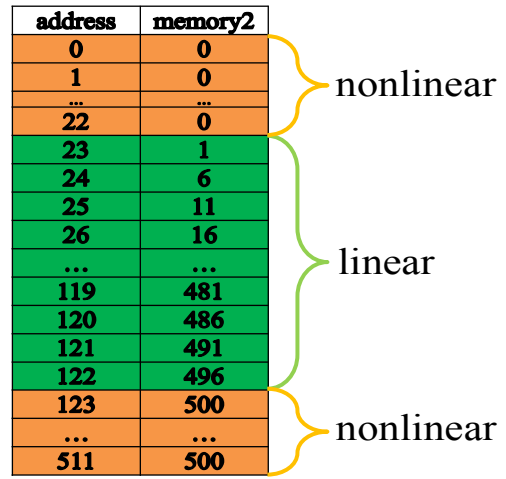




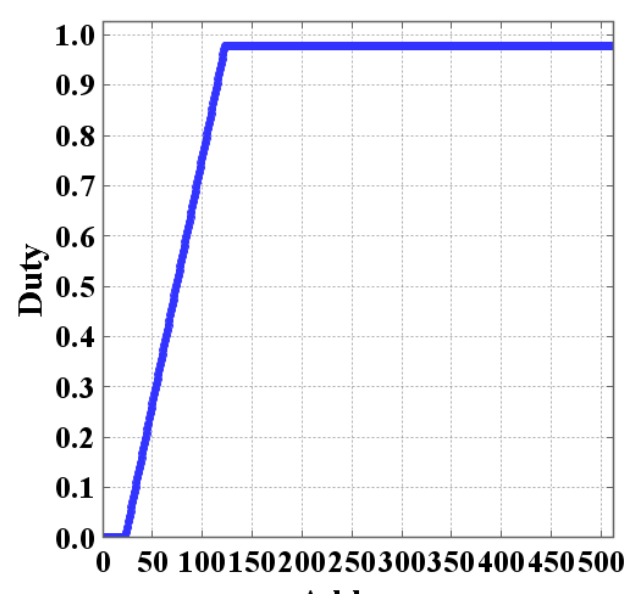

Address

Fig.7 Address vs. duty ratio at Table I

From above equations, (1) can be transformed to

$$
u(k)=u_{r e f}-\left(K_{P}+K_{I}\right) r+A\left\{y_{1}(k)+\frac{K_{I}}{A} n_{I}(k-1)-\frac{K_{D}}{A} y_{2}(k-1)\right\}
$$

Where

$$
\begin{aligned}
A & =K_{P}+K_{I}+K_{D} \\
a & =\frac{K_{I}}{A} n_{I}(k-1) \\
b & =\frac{K_{D}}{A} y_{2}(k-1)
\end{aligned}
$$

Memory 3 and memory 4 store $a$ and $b$, respectively.

In (5), $a-b$ in the term $k$ is pre-calculated in the term $k-1$ and the obtained value becomes the initial value of programmable counter of the term $k$. And, address' which indicates address of memory 2 is incremented with system clock and $u(k)$ is called from memory 2, simultaneously.

$$
\operatorname{address}^{\prime}=y_{1}(k)+a-b
$$

From (5) and (9),

$$
u(k)=u_{\text {ref }}-\left(K_{P}+K_{I}\right) r+\text { A }\{\text { address' }\}
$$

Therefore, $u(k)$ is determined as soon as $E_{o}$ is sensed.

Table I shows the address and data of memory2 at $K_{P}=5, K_{I}=0, u_{r e f}=86, \mathrm{r}=40$ in (10). Figure 6 shows address and duty ratio at Table I. You can see, Table I data have linear and nonlinear domain. And, if $K_{P}$ becomes more higher, linear domain becomes shorter.

\section{F. Overvoltage protection logic circuit}

If trigger does not occur, proposed circuit outputs overvoltage. Therefore, we use overvoltage protection logic circuit.

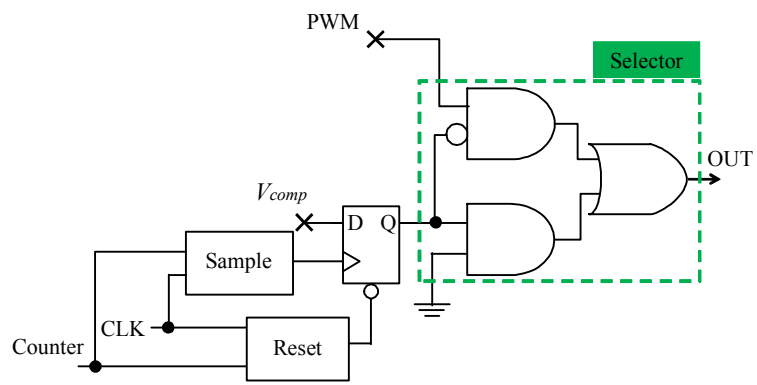

Fig. 8 The system configuration of overvoltage protection logic circuit

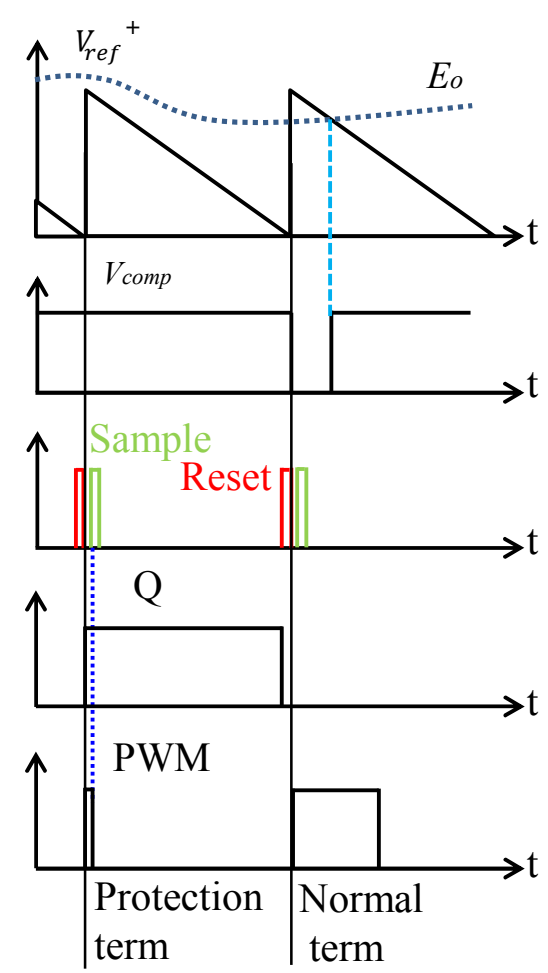

Fig.9 Protection signal flow

Table II Truth table of selector of protection logic circuit

\begin{tabular}{|c|c|}
\hline Q & OUT \\
\hline 0 & PWM \\
\hline 1 & Gnd \\
\hline
\end{tabular}

Figure 8 shows overvoltage protection circuit for proposed circuit. It is composed with selector, D-ff, sample pulse generator and reset pulse generator for D-ff.

Figure 9 shows protection signal flow, and Table II shows truth table of the selector. First, sample pulse generator occurs pulse, second, value of $\mathrm{Q}$ is decided by sample pulse and $V_{\text {comp }}$, at last OUT is decided by Table II. When sensed output voltage $E_{o}>V_{\text {ref }}{ }^{+}$, PWM signal becoming off by force. 


\section{G. The proposed circuit with Multi-phase method}

Figure 10 shows the main and the proposed control circuit configuration using a multi-phase method. The circuit is composed of five-phase.

There are some benefits to use multi-phase converter. For example, multi-phase converter is able to supply stable output current for increasing of load current because of reducing of current per phase than singlephase and reduction of ripple current. By some factors mentioned above, transient response is improved. Therefore, it has become an effective method in recently. However, there are some disadvantages that increasing of cost and circuit scale, difficulty of control by increasing of the switching element than single-phase. Therefore, appropriate design is needed to compensate above disadvantages. In proposed control system, multiphase converter is designed easily.

Figure.11 shows how to adopt the multi-phase method to the proposed circuit. The signal flow of multi-phase system block is shown in Fig. 12. These figures show how to recognize system block of second-phase.

Timing of the falling edge of PWM2 signal is determined by that of PWM signal which is first-phase. First, the timing of the rising edge of the PWM2 signal is determined by the block of Start in Fig.11. Duty ratio of PWM2 is created by adding two values of counter which are the timing of PWM falling edge and PWM2 rising edge. Block of Const creates constant value which is same value of PWM2 rising. In this time, it is 102 . Q of D-ff I and output of block of Const are added by Adder block. At block of Phase, output of Adder and value of counter are compared. And the just timing of the value of counter becomes equal to output of Adder, 0 is output form Phase block. Output of Phase block can reset output of D-ff II and determine the falling edge of PWM2 signal.

\section{EXPERIMENTAL RESULTS}

\section{A. Specifications}

The proposed control system with prototype circuit is shown in Fig.13. The digital controller part is designed with FPGA Altera Cyclone IV. Texas Instruments DAC900 is used as DAC. Linear Technology LT1719 is used as analog comparator. FDMF6705V is used as MOSFEET and driver. The DC-DC converter topology is basically same as buck converter in Fig.4(a). The buck converter with proposed controller was verified with the experimental conditions are shown in Table III. The experimental conditions with multi-phase are shown in Table IV.

\section{B. Experimental set-up}

Some experiments are performed to verify the proposed controller. Figure.14 shows experimental set-up of load current change dynamic response. We measured output voltage $E_{o}, V_{\text {comp }}$, PWM signal and output current $I_{o}$ with analog probe , $V_{\text {comp }}$ and $u(k)$ in Fig. 5 with digital probe. Current change slew rate is $50 \mathrm{~A} / \mu \mathrm{s}$.

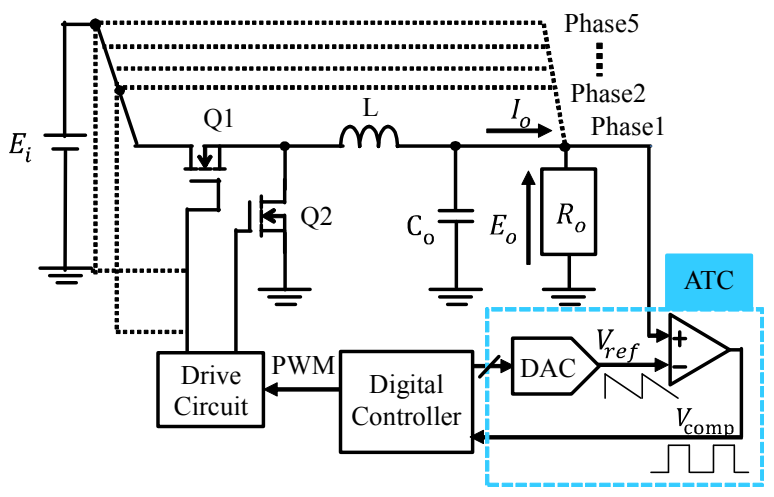

Fig.10 Proposed circuit with multi-phase

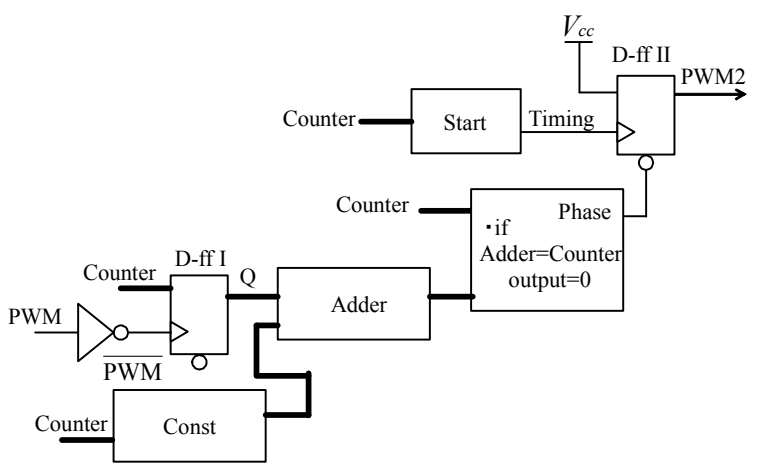

Fig.11 The system configuration of logic circuit with multi-phase method

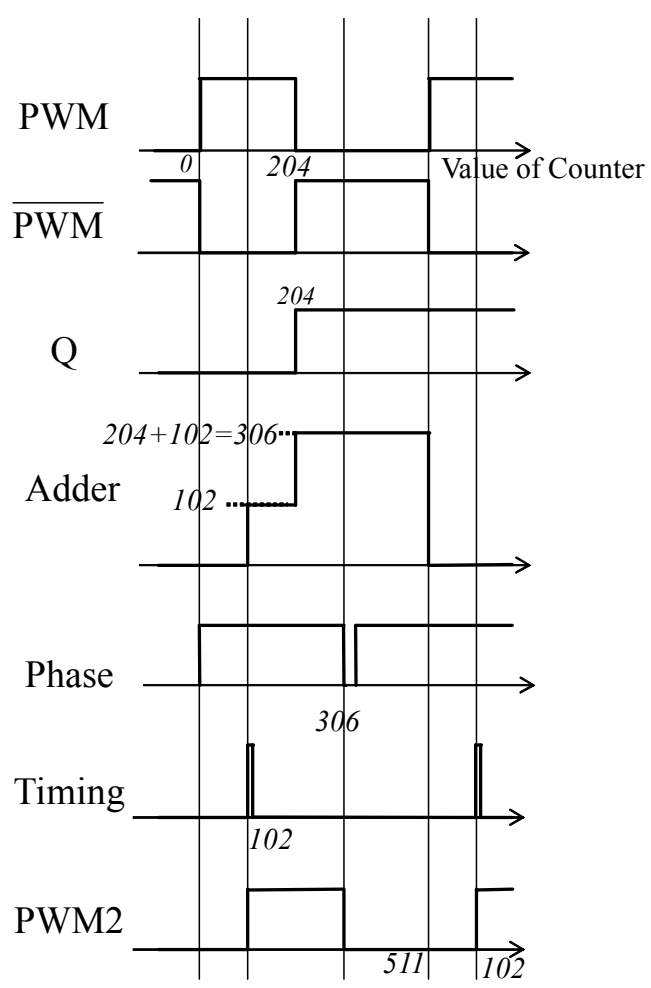

Fig.12 Signal flow of proposed circuit with multi-phase 


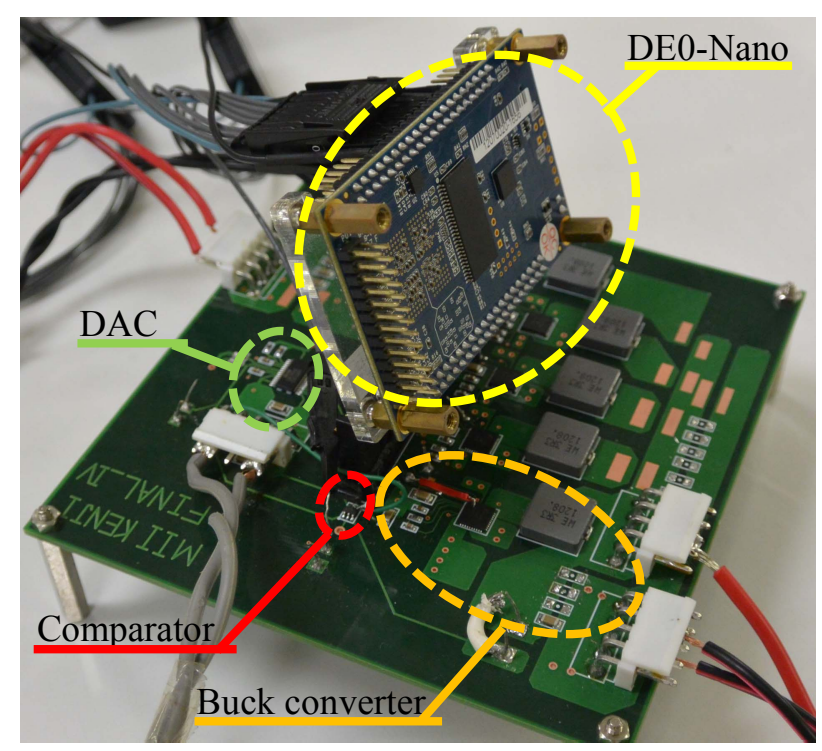

Fig.13 Prototype circuit

TABLE III
\begin{tabular}{|c|c|}
\hline Parameters $/$ Components & Value / name \\
\hline Input voltage $\mathrm{E}_{\mathrm{i}}$ & $12 \mathrm{~V}$ \\
\hline Output target voltage & $1.5 \mathrm{~V}$ \\
\hline Output current $I_{o}$ per phase & $0.3 \mathrm{~A} \sim 0.9 \mathrm{~A}$ \\
\hline Switching frequency $\mathrm{f}_{\mathrm{s}}$ & $1 \mathrm{MHz}$ \\
\hline Choke inductor L & $3.3 \mu \mathrm{H}$ \\
\hline Output capacitor $\mathrm{C}_{\mathrm{o}}$ & $10 \mu \mathrm{F}($ single $) / 57 \mu \mathrm{F}($ five $)$ \\
\hline Proportional gain $K_{P}$ & 10 \\
\hline Integral gain $K_{I}$ & 0 \\
\hline Differential gain $K_{D}$ & 0 \\
\hline $\mathrm{V}_{\text {ref }}{ }^{+}$ & 1.6 \\
\hline $\mathrm{f}_{\mathrm{CLK}}$ & $500 \mathrm{MHz}$ \\
\hline Current change slew rate & $50 \mathrm{~A} / \mu \mathrm{s}$ \\
\hline Digital PWM resolution & 9 bit \\
\hline Dr. MOS (MOSFET and driver) & Fairchild FDMF6705V \\
\hline Analog comparator & Linear Technology LT1719 \\
\hline D/A converter & Texas Instruments DAC900 \\
\hline FPGA & Terasic DE0-Nano (Cyclone IV) \\
\hline
\end{tabular}

\section{Measurement Results}

\section{1) Static characteristics}

Figure 15 shows static characteristic at $\mathrm{KP}=10$. It shows when load current with single-phase is $0.3 \sim 0.9$, output voltage is $3 \%$ of target voltage.

\section{2) Load current change transient response}

Figure 15 and 16 show experimental waveforms of load current change transient response. Both figures show $E_{o}: \quad 100 \mathrm{mV} / \operatorname{div}(\mathrm{CH} 1), \quad \mathrm{PWM}: 3 \mathrm{~V} / \operatorname{div}(\mathrm{CH} 2), V_{\text {comp }}$ : $3 \mathrm{~V} / \operatorname{div}(\mathrm{CH} 3), \quad I_{o}: 1 \mathrm{~A} / \operatorname{div}$ (CH4), $V_{\text {comp }}$ (digital):D9, $u(k)$ :D0-D8, respectively. Bottom figure is an enlargement of a part of top figure and it shows reflection time. Figure 16 and 17 show 0.3 0.9A load transient response at $K_{P}=10$. Figure 16 shows light to heavy load transient response and output voltage settled in $10.4 \mu \mathrm{s}$, under shoot is $160 \mathrm{mV}$. Figure 17 shows heavy to light load transient response and output voltage settled in $3.2 \mu \mathrm{s}$, over shoot is $58 \mathrm{mV}$. From these figures, the reflection time from sensed $V_{\text {comp }}$ to $u(k)$ change is $11.0 \mathrm{~ns}$ even in the worst case.

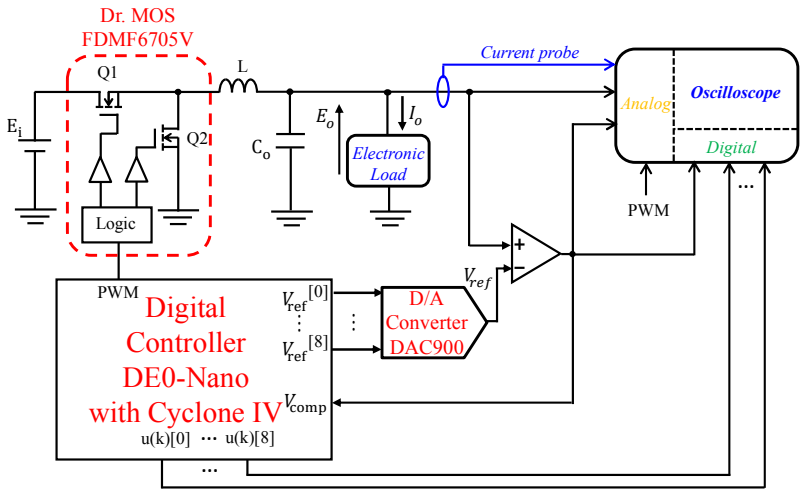

Fig. 14 Experimental set-up ststic characteristic and load current change transient response

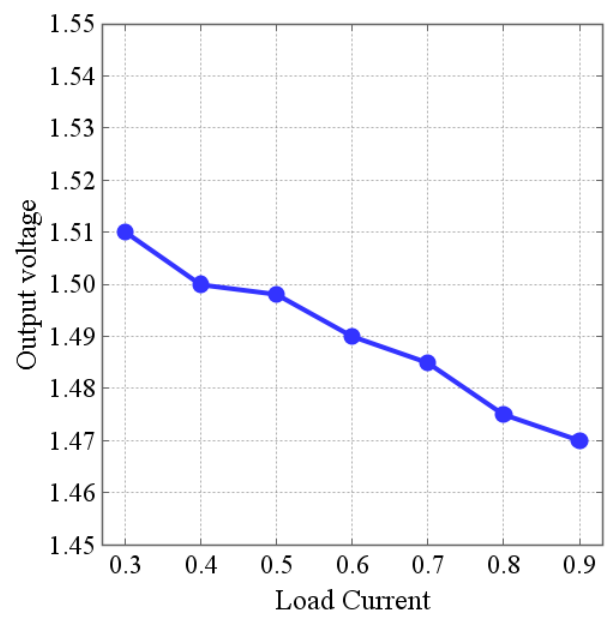

Fig. 15 Static characteristic of converter at $K_{P}=10$

Table IV is comparing the settling time of the output voltage from the proposed digitally controlled switching converter with prior work. It shows that the proposed digital controller achieves faster output settling time than existing digital controller.

1) Load current change transient response with multi-phase method

Fig18 and 19 show experimental waveforms of load current change transient response using multi-phase method. Measurement range used in this experiment is the same as single-phase. They are 0.3 0.9A load transient response at $K_{\mathrm{P}}=10$. Figure 18 shows light to heavy load transient response and output voltage settled in $15.6 \mu \mathrm{s}$, under shoot is $190 \mathrm{mV}$. Figure 19 shows heavy to light load transient response and output voltage settled in $9.0 \mu \mathrm{s}$, over shoot is $170 \mathrm{mV}$. 


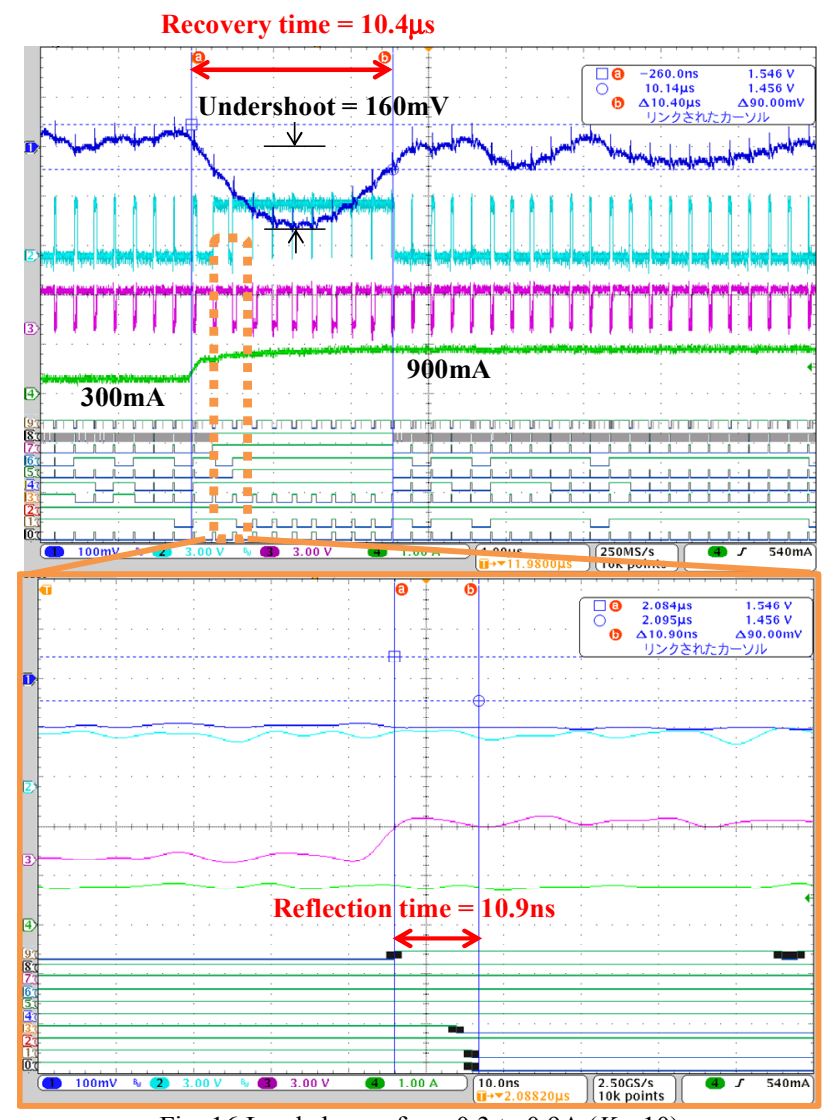

Fig. 16 Load change from 0.3 to $0.9 \mathrm{~A}\left(K_{P}=10\right)$

Recovery time $=3.2 \mu \mathrm{s}$

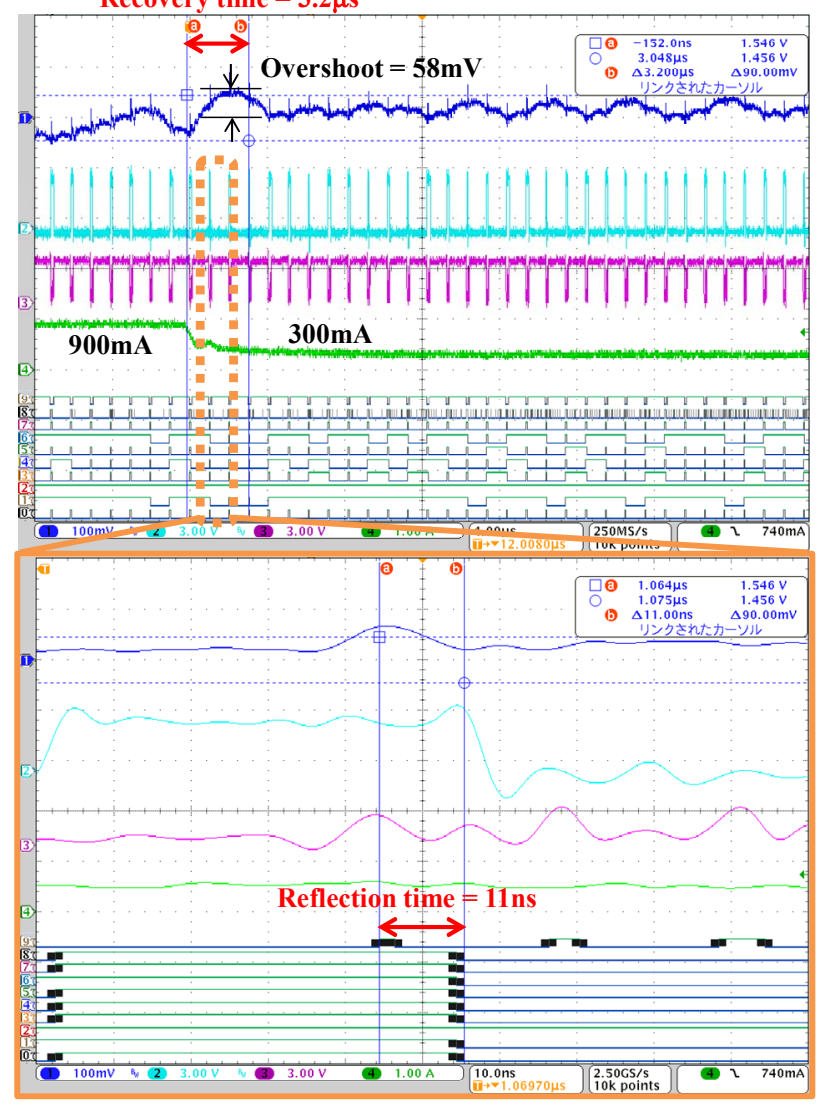

Fig. 17 Load change from 0.9 to $0.3 \mathrm{~A}\left(K_{P}=10\right)$
TABLE IV COMPARISON WITH PRIOR WORKS.

\begin{tabular}{|c|c|c|c|c|c|}
\hline & [18] & [19] & [20] & [21] & $\begin{array}{l}\text { This } \\
\text { work }\end{array}$ \\
\hline $\mathrm{L}$ & $10 \mu \mathrm{H}$ & $4.7 \mu \mathrm{H}$ & $4.7 \mu \mathrm{H}$ & $4.7 \mu \mathrm{H}$ & $3.3 \mu \mathrm{H}$ \\
\hline $\mathrm{C}$ & $10 \mu \mathrm{H}$ & $4.7 \mu \mathrm{H}$ & $4.7 \mu \mathrm{H}$ & $22 \mu \mathrm{F}$ & $10 \mu \mathrm{F}$ \\
\hline $\begin{array}{l}\text { Switching } \\
\text { frequency }\end{array}$ & $1 \mathrm{M}$ & $4 \mathrm{M}$ & $1 \mathrm{M}$ & $780 \mathrm{k}$ & $1 \mathrm{M}$ \\
\hline $\begin{array}{l}\text { Load Current } \\
\text { step }\end{array}$ & $0.45 \mathrm{~A}$ & $0.16 \mathrm{~A}$ & $0.6 \mathrm{~A}$ & $0.59 \mathrm{~A}$ & $0.6 \mathrm{~A}$ \\
\hline Input voltage & $\begin{array}{c}1.8 \\
-3.8 \mathrm{~V}\end{array}$ & $3.3 \mathrm{~V}$ & $3 \mathrm{~V}$ & $3.6 \mathrm{~V}$ & $12 \mathrm{~V}$ \\
\hline $\begin{array}{c}\text { Output target } \\
\text { voltage }\end{array}$ & $1.2 \mathrm{~V}$ & $1.5 \mathrm{~V}$ & $1.8 \mathrm{~V}$ & $1.2 \mathrm{~V}$ & $1.5 \mathrm{~V}$ \\
\hline Settling time & $3.5 \mu \mathrm{s}$ & $18 \mu \mathrm{s}$ & $15.5 \mu \mathrm{s}$ & $60 \mu \mathrm{s}$ & $10.4 \mu \mathrm{s}$ \\
\hline
\end{tabular}

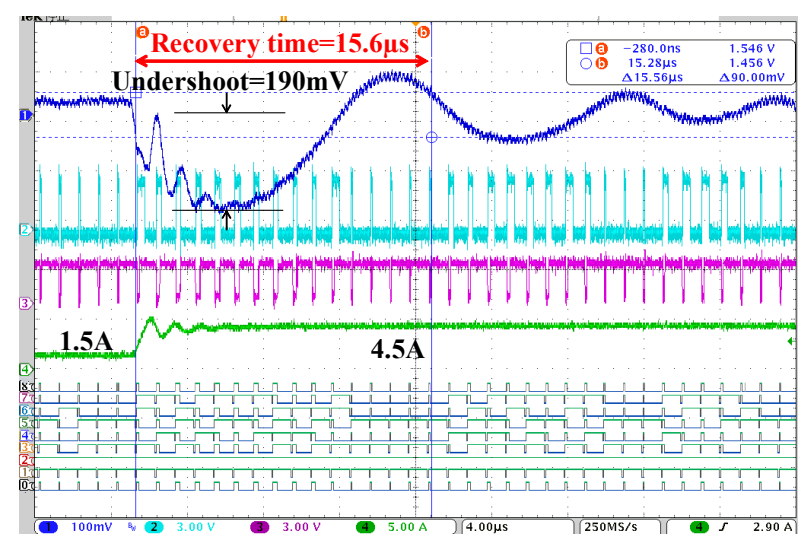

Fig18 Load change with multi-phase $1.5 \mathrm{~A}$ to $4.5 \mathrm{~A}\left(K_{P}=10\right)$

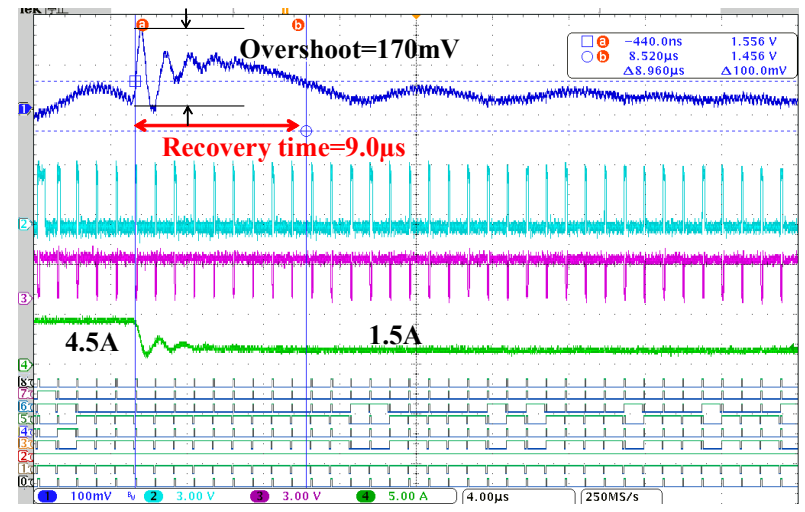

Fig.19 Load change with multi-phase $4.5 \mathrm{~A}$ to $1.5 \mathrm{~A}\left(K_{P}=10\right)$

\section{CONCLUSIONS}

In this paper, the hardware logic type digital controller for on-board SMPS, which has a very small time-delay in control loop, is confirmed with some experiments including frequency characteristic. In single-phase, settling time of proposed prototype circuit is $10.4 \mu \mathrm{s}$, and undershoot is $160 \mathrm{mV}$. This result with the specifications of table III is superior in DPWM-POLs. And the reflection time from sensed $V_{\text {comp }}$ to $u(k)$ change is $11.0 \mathrm{~ns}$ even in the worst case. The total reflection time of control system except driver circuit is in 50n sec. Therefore, it is confirmed that the proposed circuit is able to respond sub-microsecond. In addition, multi-phase proposed 
circuit achieved reduction of the output ripple. Settling time is $15.6 \mu \mathrm{s}$ and undershoot is $190 \mathrm{mV}$. From these results, it is confirmed that the proposed circuit can increase output current stably by using multi-phase. As the future work, to further enhance the PID control added to the integral control and to devise new control system, such as can be achieved faster.

\section{REFERENCES}

[1] Masatugu Tasaki. The Intranet Architecture:. "Importance of the power supply circuit in the latest FPGA board," Bellnix Corp., Japan. [Online]. Available: http://japan.xilinx.com/xcell/x151/jpxcell51 13.pdf

[2] Radic, A., Lukic, Z., Prodic, A. and de Nie, R.H., "MinimumDeviation Digital Controller IC for DC-DC Switch-Mode Power Supplies," IEEE Transactions on, vol.28, Issue.9, Sept 2013.

[3] Yue Wen, and Trescases, O., "DC-DC converter with digital adaptive slope control in auxiliary phase to achieve optimal transient response," Applied Power Electronics Conference and Exposition, IEEE, April 2014.

[4] Corradini, L., Bjeletic, A., Zane, R. and Maksimovic, D., "Fully digital hysteretic modulator for DC-DC switching converters," Energy Conversion Congress and Exposition IEEE,Sept 2009

[5] Wangxin Huang, Abu Qahouq, J. A. "Tuning of a digital proportional-integral compensator for DC-DC power converter," Applied Power Electronics Conference and Exposition IEEE, March 2013.

[6] Huerta,S.C, Alou, P., Garcia, O., and Oliver, J.A., "Hysteretic Mixed-Signal Controller for High-Frequency DC-DC Converters Operating at Constant Switching Frequency," Power Electronics, IEEE Transactions on Vol.27, Issue. 6 June 2012.

[7] Yingyi Yan, Lee, F.C., and Mattavelli, P., "Comparison of Small Signal Characteristics in Current Mode Control Schemes for Point-of-Load Buck Converter Applications," Power Electronics, IEEE Transactions on Vol.28, Issue, 7 July 2013

[8] Ahmad, H., and Bakkaloglu, B., "A digitally controlled DC-DC buck converter using frequency domain ADCs," Applied Power Electronics Conference and Exposition, IEEE Feb. 2010

[9] Barai, M., SenGupta, S., and Biswas, J., "Dual-Mode MultipleBand Digital Controller for High-Frequency DC-DC Converter," Power Electronics, IEEE Transactions on, Vol24, Issue3 March 2009

[10] Babazadeh, A., Corradini, L., and Maksimovic, D., "Near timeoptimal transient response in DC-DC buck converters taking into account the inductor current limit," Energy Conversion Congress and Exposition, IEEE Sept. 2009

[11] Ahmad, H., and Bakkaloglu, B., "A DC-DC digitally controlled buck regulator utilizing multi-bit $\Sigma \Delta$. frequency discriminators," Applied Power Electronics Conference and Exposition, IEEE, Feb. 2008

[12] Jakobsen, L.T., Schneider, H., and Andersen, M.A.E., "Comparison of state-of-the-art digital control and analogue control for high bandwidth point of load converters," Applied Power Electronics Conference and Exposition, IEEE Feb. 2008

[13] Jing Wang, Prodic, A., and Wai Tung Ng, "Flyback transformer based transient suppression method for digitally controlled buck converters," Energy Conversion Congress and Exposition,IEEE, Sept. 2011

[14] Yingyi Yan, Lee, F.C., and Mattavelli, P., "Dynamic performance comparison of current mode control schemes for Point-of-Load Buck converter application," Applied Power Electronics Conference and Exposition, IEEE, Feb. 2012

[15] Shi-Quan Fan, Li Geng, and Sheng-Lei Wang, "An algorithmic ADC applied in digital controlled switched DC-DC converters," Solid-State and Integrated Circuit Technology, IEEE International Conference on, Nov. 2010

[16] Ng, W.T., Wang, J., Ng, K., Prodić, A., Kawashima, T., Sasaki, M., and Nishio, H., "Digitally controlled integrated DC-DC converters with fast transient response," Radio-Frequency Integration Technology,IEEE International Symposium on, Jan. 9 2009-Dec. 112009
[17] Abbas, G., Sturtzer, E., and Abouchi, N., "Design and implementation of a PWM-based digital controller for a highfrequency dc-dc buck converter working in CCM using classical control techniques," NEWCAS Conference, IEEE International on , June 2010

[18] Huey Chain Foong, Yuanijin Zheng, Yen Kheng Tan, and Meng Tong Tan "Fast-Transient Integrated Digital DC-DC Converter With Predictive and Feedforward Control," IEEE Transactions on Vol.59,Issue, 7,July 2012

[19] Shuibao Guo, Yanxia Gao, Yanping Xu, and Xuefang "Digital PWM controller for high-frequency low-power DC-DC switching mode power supply," Power Electronics and Motion Control Conference, 2009. IPEMC '09. IEEE 6th International, May 2009

[20] Lee A.T.L, and Chan,P.C.H, "Adaptive prediction in digitally controlled buck converter with fast load transient response," IEEE 13th Workshop on June 2012

[21] Chien-Hung Tsai, Chun-Hung Yang, Jiunn-Hung Shiau, and BoTing Yeh, "Digitally Controlled Switching Converter With Automatic Multimode Switching," Power Electronics, IEEE Transactions on.Vol.29,Issue.4,April 2014

[22] Yoichi Ishizuka, Masao Ueno, Ichiro Nishikawa, Akira Ichinose and Hirofumi Matsuo, "A Low-Delay Digital PWM Control Circuit for DC-DC Converters", in Proc. 2008 IEEE Applied Power Electronics Conference (APEC), CA, USA, 2008, pp.579586 .

[23] Y. Ishizuka, F. Hirose, Y. Yamada, H. Matsuo, "A time-delay suppression technique for DPWM control circuit", in Proc. 2009 IEEE Telecommunications Energy Conference (INTELEC), pp.16.

[24] Y. Ishizuka, Y. Yamada, F. Hirose, M. Nishi, H. Matsuo, "A design for small time-delay control circuit for DPWM- POL" in Proc. 2010 IEEE Applied Power Electronics Conference and Exposition (APEC), pp. 1879-1884.

[25] Y. Ishizuka, F. Hirose, Y. Yamada, H. Matsuo, "A fast transient response technique for DPWM DC-DC converters", in Proc. 2010 IEEE Telecommunications Energy Conference (INTELEC), pp. $1-6$.

[26] Yoichi Ishizuka, Kenji Mii, Daisuke Kanemoto, Tamotsu Ninomiya, "Frequency Response Analysis of Proposed Digital Control System for DPWM-POL“, in Proc. 2013 IEEE Power Electronics and Applications European Conference (EPE), pp. 110. 